\title{
Exposure to high-frequency electromagnetic field triggers rapid uptake of large nanosphere clusters by pheochromocytoma cells
}

This article was published in the following Dove Press journal: International Journal of Nanomedicine

\author{
Palalle G Tharushi Perera' \\ The Hong Phong Nguyen ${ }^{2}$ \\ Chaitali Dekiwadia ${ }^{3}$ \\ Jason V Wandiyanto' \\ Igor Sbarski' \\ Olga Bazaka ${ }^{4}$ \\ Kateryna Bazaka ${ }^{5}$ \\ Russell J Crawford ${ }^{4}$ \\ Rodney J Croft ${ }^{6}$ \\ Elena P Ivanova ${ }^{4}$ \\ 'Faculty of Science, Engineering and \\ Technology, Swinburne University of \\ Technology, Hawthorn, VIC, Australia; \\ ${ }^{2}$ Faculty of Applied Sciences, Ton \\ Duc Thang University, Ho Chi Minh \\ City, Vietnam; ${ }^{3}$ RMIT Microscopy \\ and Microanalysis Facility, College of \\ Science, Engineering and Health, RMIT \\ University, Melbourne, VIC, Australia; \\ ${ }^{4}$ School of Science, RMIT University, \\ Melbourne, VIC, Australia; ${ }^{5}$ School \\ of Chemistry, Physics, Mechanical \\ Engineering, Queensland University of \\ Technology, Brisbane, QLD, Australia; \\ ${ }^{6}$ School of Psychology, Illawarra \\ Health and Medical Research Institute, \\ University of Wollongong, Wollongong, \\ NSW, Australia
}

Correspondence: Elena P Ivanova School of Science, RMIT University, PO Box 2476, Melbourne, VIC 300I, Australia

Tel +6I 399253395

Email elena.ivanova@rmit.edu.au
Background: Effects of man-made electromagnetic fields (EMF) on living organisms potentially include transient and permanent changes in cell behaviour, physiology and morphology. At present, these EMF-induced effects are poorly defined, yet their understanding may provide important insights into consequences of uncontrolled (e.g., environmental) as well as intentional (e.g., therapeutic or diagnostic) exposure of biota to EMFs. In this work, for the first time, we study mechanisms by which a high frequency (18 GHz) EMF radiation affects the physiology of membrane transport in pheochromocytoma PC 12, a convenient model system for neurotoxicological and membrane transport studies.

Methods and results: Suspensions of the PC 12 cells were subjected to three consecutive cycles of $30 \mathrm{~s}$ EMF treatment with a specific absorption rate (SAR) of $1.17 \mathrm{~kW} \mathrm{~kg}^{-1}$, with cells cooled between exposures to reduce bulk dielectric heating. The EMF exposure resulted in a transient increase in membrane permeability for $9 \mathrm{~min}$ in up to $90 \%$ of the treated cells, as demonstrated by rapid internalisation of silica nanospheres (diameter $d \approx 23.5 \mathrm{~nm}$ ) and their clusters $(d \approx 63 \mathrm{~nm})$. In contrast, the PC 12 cells that received an equivalent bulk heat treatment behaved similar to the untreated controls, showing lack to minimal nanosphere uptake of approximately $1-2 \%$. Morphology and growth of the EMF treated cells were not altered, indicating that the PC 12 cells were able to remain viable after the EMF exposure. The metabolic activity of EMF treated PC 12 cells was similar to that of the heat treated and control samples, with no difference in the total protein concentration and lactate dehydrogenase (LDH) release between these groups.

Conclusion: These results provide new insights into the mechanisms of EMF-induced biological activity in mammalian cells, suggesting a possible use of EMFs to facilitate efficient transport of biomolecules, dyes and tracers, and genetic material across cell membrane in drug delivery and gene therapy, where permanent permeabilisation or cell death is undesirable.

Keywords: electromagnetic fields, EMFs, $18 \mathrm{GHz}$, PC 12 neuronal cells, membrane permeability, microwave

\section{Introduction}

Life appeared and developed within the multitude of natural electromagnetic fields (EMFs), but this natural environment has drastically changed with the introduction of the ever-growing spectrum of man-made EMFs. Effects on biological matter exposed to artificial EMFs have been a focus of research investigation since the 18 th century, ${ }^{1}$ with research effort becoming more intense now due to the growing prevalence of power transmission devices and consumer goods (eg, microwave [MW] ovens) that rely on electromagnetic radiation to perform their functions. ${ }^{2-4}$ In recent years, a rapid growth in mobile communication systems, wireless and radio communications, ${ }^{5,6}$ and the associated surge in the usage of personal communication devices like tablets, portable 
computers, Wi-Fi-enabled "smart" phones, televisions, and cameras has significantly increased the likelihood of environmental exposure of humans and other organisms to $\mathrm{EMFs}^{2,7}$ and to MW radiation in particular. It is of utmost importance to explore and understand the effects arising from the interaction of EMFs with living entities at the micro and nano scale.

MW radiation is a part of the electromagnetic spectrum consisting of frequencies from $300 \mathrm{MHz}$ to $300 \mathrm{GHz}$, ${ }^{1,4}$ with the corresponding wavelength in the range of $1 \mathrm{~m}-1 \mathrm{~mm} .^{1,8}$ Early studies based on modeling efforts regarded such EMFs to be not sufficiently strong to induce significant biophysical or biochemical changes in living systems and affect their physiological functions. Recent findings, however, revealed evidence that depending on the amount of energy delivered into the system, MW radiation may induce a variety of molecular transformations that may in turn lead to modulation of chemical events that take place on the cell surface, ${ }^{1,9}$ including molecular binding, signaling, and transmembrane transport. Previous reports stated that treatment using EMF of $18 \mathrm{GHz}$ was able to induce a reversible increase in membrane permeability in different Gram-negative and Gram-positive bacterial species, including Planococcus maritimus KMM 3738, Staphylococcus aureus CIP65.8 ${ }^{\mathrm{T}}$, S. aureus ATCC 25923, Staphylococcus epidermidis ATCC $14990^{\mathrm{T}}$, and Escherichia coli, and yeast and red blood cells. ${ }^{10,11}$ Although permeabilization was observed in all cell types, thereby suggesting a similar mechanism of induction, the differences in cell membrane fatty acid and phospholipid composition, such as the presence of pentadecanoic fatty acid or phosphatidyl-glycerol, determined the specific dose of 18-GHz EMF exposure required to induce permeabilization and the size and number of nanoparticles that could be internalized by thus-treated cells. ${ }^{12}$ This phenomenon presents a motivating opportunity as an alternative method for rapidly inducing a transient increase in membrane permeability as a means to attain more efficient uptake of biomolecules, dyes and tracers, and genetic material by cells in drug delivery and gene therapy applications. This approach may be particularly useful for applications where permanent membrane damage or cell death is not desired, since the aforementioned treatment did not negatively affect cell viability regardless of the microorganism species being treated. ${ }^{12-14}$ However, in order to facilitate the translation of this phenomenon into real-life applications, more effort is needed to understand the mechanisms by which EMFs modulate key cellular processes and affect cell viability, particularly in mammalian cells.
The aim of this study was to explore the bioeffects of 18-GHz EMFs on eukaryotic cells and investigate whether the exposure of pheochromocytoma cells to such fields would affect membrane permeabilization, proliferation rates, and metabolic status. The present study focuses on the possible effect of EMFs at $18 \mathrm{GHz}$ with short exposures of 30 seconds at a power of $17 \mathrm{~W}$ on a mammalian cell line (PC 12). The hypothesis behind the present study is that at this fixed frequency of $18 \mathrm{GHz}$, nonionizing electromagnetic radiation encounters a polar molecule (water) and transfers a fraction of its energy to this molecule, driving it to oscillate which in turn has an effect on other cellular constituents. This research is significant because of the following reasons.

1. Just as man-made electromagnetic radiation, nanoparticles are becoming increasingly ubiquitous, being used in a very wide range of medical and cosmetic applications, as well as being released into the environment by many industries. Nanoparticle toxicity is closely related to their uptake and accumulation by cells. Therefore, it is important to understand how nanoparticle uptake is affected by even a brief exposure of human cells to EMF of low intensity.

2. Closely related to the previous point, nanoparticles are increasingly being used for medical visualization, cancer treatment, and delivery of drugs and biomolecules. The efficacy of some of these applications is inherently linked to the ability of nanoparticles to cross the cellular membrane to deliver the treatment intracellularly. Thus, it is the aim of this research to test whether $18-\mathrm{GHz}$ EMF can be applied to cells with the aim to induce a very specific set of outcomes, ie, a temporary increase in membrane permeability and nanoparticle uptake, while minimizing other biological effects, eg, changes in metabolic activity, of such an exposure.

The pheochromocytoma PC 12 cell line was selected as a model as it is easy to culture and because there is a large amount of background knowledge available on its proliferation and differentiation in response to pharmacological manipulation or exposure to other types of treatment. ${ }^{15,16}$

\section{Materials and methods PC 12 cells origin and growth conditions}

Pheochromocytoma cells were derived from the rat adrenal medulla. ${ }^{17}$ The PC 12 cell line used in this study was purchased from the American Type Culture Collection (Manassas, VA, USA) and cultured in a complete Gibco ${ }^{\mathrm{TM}}$ RPMI medium (Thermo Fisher Scientific, Waltham, MA, USA) supplemented with $10 \%$ Gibco $^{\mathrm{TM}}$ horse serum 
(Thermo Fisher Scientific), 5\% Gibco ${ }^{\mathrm{TM}}$ fetal bovine serum (Thermo Fisher Scientific), and 1\% Gibco ${ }^{\mathrm{TM}}$ penicillin/ streptomycin (Thermo Fisher Scientific). Supplements were stored as aliquots at $-20^{\circ} \mathrm{C}$. Stock solutions of the PC 12 cells were prepared in a medium containing 90\% FBS and 10\% dimethyl sulfoxide and stored in liquid nitrogen. The cells were maintained at $37^{\circ} \mathrm{C}$ with $5 \% \mathrm{CO}_{2}$ in a $95 \%$ humidified incubator. The medium was changed every 2 days and passaged accordingly when the confluence reached $90 \%$.

\section{EMF exposure and sample preparation}

EMF treatments of the PC 12 cells were carried out according to a previously developed procedure as described elsewhere, ${ }^{10,12}$ depicted in Figure 1. The increase in temperature was monitored in the presence of EMF radiation for 60 seconds. The cells were exposed to EMFs in 30-second long cycles, which allowed for the temperature to be maintained below $37^{\circ} \mathrm{C}$ (Figure 1C).

The MW apparatus (Vari-Wave Model LT 1500; Lambda Technologies, Morrisville, NC, USA) used in the study has an option of varying the frequency range from 5 to $18 \mathrm{GHz}$. The frequency was adjusted to a fixed value of $18 \mathrm{GHz}$ and the power ranged from $17 \mathrm{~W}$, as described elsewhere. ${ }^{10,11}$ In brief, the micro Petri dish (35 mm diameter; Griener BioOne, Frickenhausen, Germany) with the sample was placed on the ceramic pedestal (Pacific Ceramics, Sunnyvale, CA, USA; insert symbol $=160$, loss tangent $<10^{-3}$ ) on the hot spot-free location, identified by electric field modeling using CST Microwave Studio 3D Electromagnetic Simulation Software (CST of America, Framingham, MA, USA) and
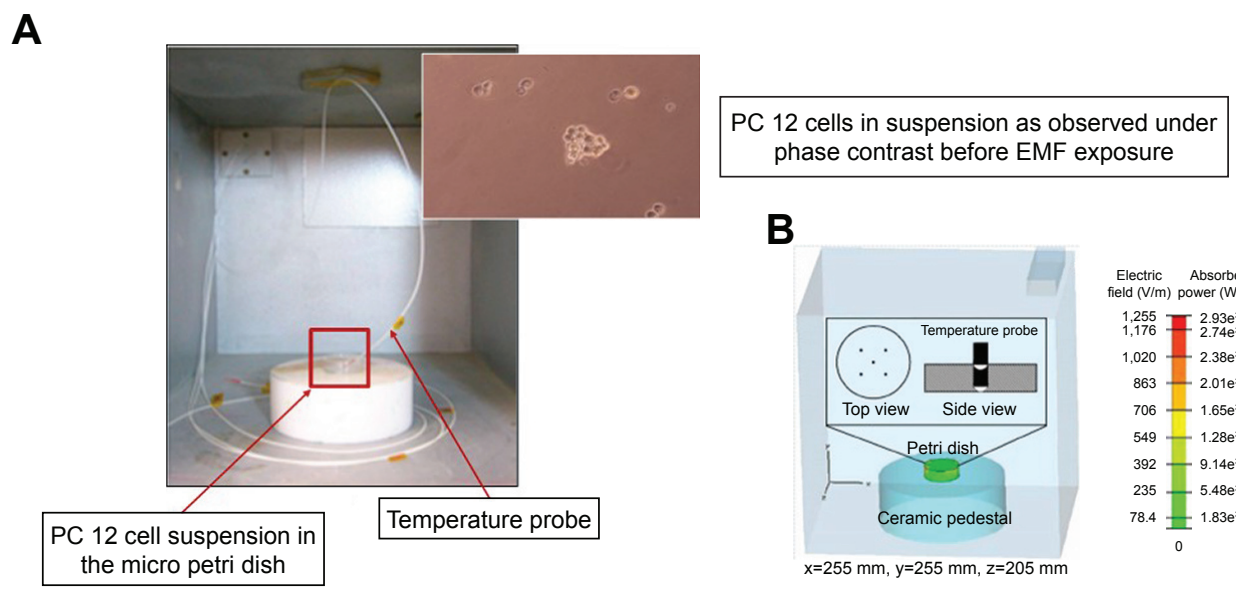

B
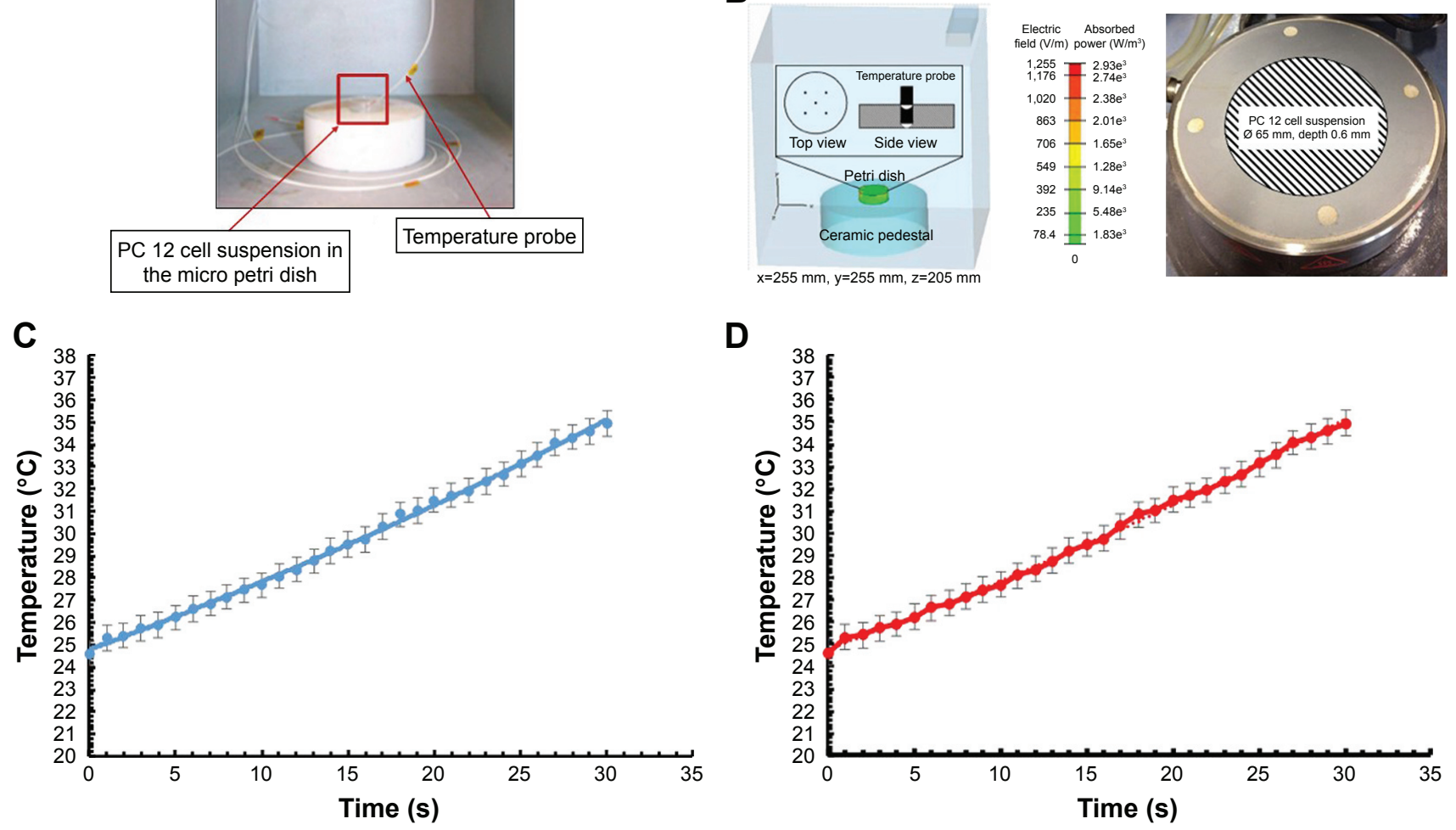

Figure I The experimental set up of EMF treatments of PC 12 cell suspensions.

Notes: (A) The microwave chamber. The temperature probe was placed inside the PC 12 suspension, which was placed on the ceramic pedestal. Insets of PC 12 as visualized under phase contrast microscopy in preparation for EMF exposure. Cells appear to be floating in the suspension in a group of few cells. (B) Absorbed power and electric field modeling performed using CST Microwave Studio 3D Electromagnetic Simulation Software; the image depicts the position of the tip of the temperature probe (side and top view); on the right is the Peltier heating stage and the PC 12 suspension was spread on the plate (diameter $=65 \mathrm{~mm}$, depth of suspension $=0.6 \mathrm{~mm}$ ). (C) Temperature rise in the suspension of PC 12 cells in the presence of EMF radiation. The rise in temperature of the cells in the suspension during EMF treatment was monitored every second for the first 60 seconds. EMF treatments were carried out only for 30 seconds to prevent the overheating of cells. (D) Heat profile in the suspension of PC I 2 in the absence of EMF radiation. In the Peltier heating graph, the temperature profile during EMF treatments was replicated and the cells were exposed to the same temperature but in the absence of EMF radiation.

Abbreviation: EMF, electromagnetic field. 
experimental temperature measurements. The cell density of PC 12 used for EMF exposure was adjusted to $6 \times 10^{4}$ cells $/ \mathrm{mL}$ in PBS using a hemocytometer (Paul Marienfeld GmbH \& Co KG, Lauda-Konigshofen, Germany). The PC 12 cell suspensions were exposed to the EMF for a duration of 30 seconds. The temperature rise in the cell suspension was monitored using a built-in temperature probe, a Luxtron Fiber Optic Temperature Unit (LumaSense Technologies, Santa Clara, CA, USA). After the MW treatment, the sample was cooled down to $25^{\circ} \mathrm{C}$ for 2 minutes. The $\mathrm{MW}$ chamber was cooled using ice packs to bring the temperature to $25^{\circ} \mathrm{C}$. The sample was exposed to three cycles (30 seconds; 2 minutes cooling) of MW radiation while keeping all the other environmental factors constant.

\section{Dosimetry}

$$
\mathrm{SAR}=\mathrm{c} \times\left.\frac{\partial \mathrm{T}}{\partial \mathrm{t}}\right|_{t=0}
$$

The specific absorption rate (SAR) was calculated by assuming that the dielectric loss tangent describing the energy dissipation was the same as water at $25^{\circ} \mathrm{C}$ and $18 \mathrm{GHz}$ as described elsewhere. ${ }^{18}$

SAR is calculated using Equation 1, where c, the specific heat capacity of the medium, was similar to that of water, which is $4.18 \mathrm{~kJ} \mathrm{~kg}^{-1 \circ} \mathrm{C}^{-1}$, and $\left.\frac{\partial \mathrm{T}}{\partial \mathrm{t}}\right|_{t=0}$ is the time derivative of the temperature determined at $\mathrm{t}=0 \mathrm{~s}\left({ }^{\circ} \mathrm{C} \mathrm{s}^{-1}\right)$. It was essential to determine the SAR value as it is considered as an accurate measure of energy absorbed by a biological material. ${ }^{18,19}$ Five different locations on the petri dish were used to gather temperature measurements, and spatial averaging was used in determining SAR using 150 measurements. The experiment was designed to prevent overheating of the PC 12 cells by avoiding hot spots while maintaining adiabatic conditions.

\section{Peltier heat treatment}

The temperature profile during the EMF exposure was replicated using bulk heat treatment by using the Peltier plate heating/cooling system (TA Instruments, New Castle, DE, USA). A 2-mL aliquot of PC 12 cell suspension was spread on the Peltier stage (Figure 1B) and was subjected to heating from $25^{\circ} \mathrm{C}$ to $37^{\circ} \mathrm{C}$ for a period of 30 seconds, which was followed by cooling to $25^{\circ} \mathrm{C}$ for 2 minutes before the application of the next heat treatment to replicate the changes in temperature conditions experienced by EMF-treated cells. A portable infrared/thermal monitoring camera (Cyclope 330S; Minolta, Osaka, Japan) was used to detect the temperature rise and fall during the cycle. The Peltier-treated PC 12 cells were used as the heat-treated control group.

\section{Controls}

PC 12 cells grown in full serum medium were used as the untreated control group.

\section{Cellular uptake of silica nanospheres}

Fluorescent silica nanospheres with a diameter of $23.5 \pm 0.2 \mathrm{~nm}$ (fluorescein isothiocyanate [FITC]) (Corpuscular Inc, Cold Spring, NY, USA) were used to study the permeability of PC 12 cells. The membrane phospholipids were stained using carbocyanine DIL (1, $1^{\prime}$-dioctadecyl3,3,3',3'-tetramethylindocarbocyanine perchlorate) dye (Thermo Fisher Scientific). Immediately following EMF exposure, the nanospheres were added into the cell suspension at a concentration of $10 \mu \mathrm{g} / \mathrm{mL}$. After 5 minutes of incubation, the samples were washed twice using PBS and centrifuged at $1,300 \mathrm{rpm}$ for 5 minutes at $25^{\circ} \mathrm{C}$. The procedure was repeated for the heat-treated cells and the untreated controls, where the cell samples were mixed with $10 \mu \mathrm{L}$ of FITC nanosphere solution. A $150-\mu \mathrm{L}$ aliquot of the sample was visualized using a Fluoview FV10i-W inverted microscope (Olympus Corporation, Tokyo, Japan).

\section{Permeability coefficient of EMF-treated PC 12 cells}

The nanosphere uptake following EMF exposure was quantified according to the fluorescence intensity generated from the silica nanospheres internalized by the PC 12 cells using a FLUOstar Omega microplate reader (BMG LABTECH, Cary, NC, USA), a method that has been used previously. ${ }^{12}$ The mass $m$ of a silica nanosphere was determined from the density of silica $\rho$ and the volume of a silica nanosphere $\mathrm{V}$, related to the radius $\mathrm{r}$ as $\mathrm{V}=\frac{4}{3} \pi \mathrm{r}^{3}$. The average radius of a green nanosphere was $11.75 \times 10^{-7} \mathrm{~cm}$ (Corpuscular), and hence the volume was estimated to be $6.8 \times 10^{-18} \mathrm{~cm}^{3}$, and mass $1.8 \times 10^{-17} \mathrm{~g}$. The mass of a single nanosphere was used to calculate the number of internalized nanospheres. The sample preparation was carried out according to the method used for confocal laser scanning microscopy (CLSM) analysis. The correlation of the nanosphere concentration and the fluorescence intensity was established using a calibration curve. Standards of nanosphere concentrations were prepared $(0.5,1,2,4,6,8,10,12 \mu \mathrm{g} / \mathrm{mL})$.

Confocal laser scanning images were used in quantifying nanosphere uptake by counting the number of cells 
emitting green fluorescence in parallel with the cells that are not permeabilized. Ten different fields of view were analyzed. The transient increase in permeability is expressed as a percentage.

\section{Dynamic light scattering (DLS) of silica nanospheres distribution}

The particle distribution of silica nanospheres was analyzed using DLS (Zetasizer Nano ZS ZEN3600; Malvern Instruments, Malvern, UK). For DLS experiments, a 1-mL aliquot of the nanosphere stock solution was sonicated for 15 minutes. After sonication, $10 \mu \mathrm{L}$ was withdrawn and diluted in $2 \mathrm{~mL}$ of sterile milliQ water. The mean effective diameter of the nanospheres and their clusters was measured.

\section{Transmission electron microscopy (TEM)}

After 5 minutes of incubation in the presence of nanospheres following EMF exposure, cell suspensions were pelleted by centrifugation at $1,300 \mathrm{rpm}$ for 5 minutes at $25^{\circ} \mathrm{C}$. The cells were then washed twice with PBS (10 mM, pH 7.4) in order to remove any unbound nanospheres. The cell pellet was conditioned with $0.1 \mathrm{M}$ sodium cacodylate buffer ( $\mathrm{pH}$ 7.4). The cell pellet was then resuspended in primary fixative of $4 \%$ paraformaldehyde and $2.5 \%$ glutaraldehyde in $0.1 \mathrm{M}$ sodium cacodylate buffer overnight at $4^{\circ} \mathrm{C}$ and washed thrice in cacodylate buffer for 10 minutes each. The cells were postfixed in $1 \%$ osmium tetroxide and potassium ferrocyanide for 1 hour followed by three washes in distilled water for 10 minutes each. The cells were dehydrated through a graded ethanol series $(50 \%, 70 \%$, and $90 \%)$ for 15 minutes. The cells were further dehydrated by passing through $100 \%$ ethanol series twice followed by $100 \%$ acetone series for 30 minutes at room temperature. The cells were further infiltrated with a 1:1 ratio of acetone:Spurr's resin mixture overnight. After that, the cells were completely exchanged in 100\% Spurr's resin twice for 3 hours each. The resin samples were further polymerized at $70^{\circ} \mathrm{C}$ for 48 hours. The final block was trimmed, then cut into ultrathin sections (90 nm thickness) using a Leica Ultracut Ultramicrotome (Leica Microsystems, Wetzlar, Germany) with a diamond knife (Diatome, Hatfield, PA, USA). Sections were placed onto 200 mesh copper grids and examined using a JEM 1010 instrument (JEOL, Tokyo, Japan). Approximately 40 TEM images were taken at $\times 5,000$ and $\times 10,000$ magnifications for sample analysis.

\section{Cellular morphology}

A scanning electron microscope, FeSEM SUPRA 40VP (Carl Zeiss Meditec AG, Jena, Germany), with a primary beam energy of $3 \mathrm{kV}$ was used. A $100-\mu \mathrm{L}$ aliquot of cells in PBS was placed on a glass cover slip (ProSciTech, Kirwan, Australia) in duplicate. The glass cover slips were then washed with nanopure $\mathrm{H}_{2} \mathrm{O}$ (resistivity of $18.2 \mathrm{MW} / \mathrm{cm}$ ) and dried with $99.99 \%$ purity nitrogen gas. The PC 12 cells exposed to EMF of $18 \mathrm{GHz}$ were fixed in a cocktail of $4.0 \%$ paraformaldehyde and $2.5 \%$ glutaraldehyde for 30 minutes. The cells were then dehydrated by passing through a graded ethanol series $(20 \%, 40 \%, 60 \%, 80 \%$, and 100\%) for 15 minutes. Before imaging, the fixed cells were subjected to gold sputtering ( $6 \mathrm{~nm}$ thick) using a NeoCoater MP-19020NCTR (JEOL). The same procedure was applied to non-treated and heat-treated PC 12 cells. Scanning electron microscopy (SEM) images (10) of different magnifications were captured and analyzed.

\section{Cell viability}

The viability of PC 12 cells was determined using the LIVE/DEAD Viability/Cytotoxicity Kit (Thermo Fisher Scientific). The viability of the EMF-treated cells and the controls was monitored immediately after treatment and confirmed through three technical replicates. CLSM was used in assessing the number of viable cells; 10 fields of view were analyzed per sample type.

\section{Cell proliferation}

Cell proliferation was determined using the CellTiter $96^{\circledR}$ $\mathrm{AQ}_{\text {ueous }}$ One Solution Cell Proliferation Assay (Promega Corporation, Fitchburg, WI, USA). The assay was performed by adding tetrazolium compound to the EMF-treated PC 12 cell culture at a $10 \%$ ratio of the final volume. This allowed for the reduction of MTS (3-(4,5-dimethylthiazol2-yl)-5-(3-carboxymethoxyphenyl)-2-(4-sulfophenyl)-2Htetrazolium) to formazan, which resulted in the formation of a purple-colored precipitate. After incubation for 90 minutes at $37^{\circ} \mathrm{C}$, the absorbance was recorded at a wavelength of $490 \mathrm{~nm}$ using a FLUOstar Omega microplate reader (BMG LABTECH).

\section{Protein concentration}

The total protein content present in the EMF-treated cells and the non-treated cells was determined using the Bicinchoninic Acid Protein (BCA) Assay (Sigma-Aldrich Co, St Louis, MO, USA). The PC 12 cells were lysed with $150 \mu \mathrm{L}$ of protein lysis reagent (Sigma-Aldrich $\mathrm{Co}$ ) and incubated for 15 minutes at $25^{\circ} \mathrm{C}$. After incubation, the cells were spun at $1,300 \mathrm{rpm}$ for 5 minutes at $25^{\circ} \mathrm{C}$. Then, $25 \mu \mathrm{L}$ of the supernatant was placed onto a 96-well plate (Sarstedt, Germany) 
and $200 \mu \mathrm{L}$ of BCA reagent (bicinchoninic acid solution and copper (II) sulfate pentahydrate $4 \%$ ) was added. The sample was then incubated for 30 minutes at $37^{\circ} \mathrm{C}$, and the absorbance was recorded at $562 \mathrm{~nm}$ using the FLUOstar Omega microplate reader (BMG LABTECH).

\section{Cell integrity}

The release of lactate dehydrogenase (LDH) by the EMFtreated PC 12 cells was tested using the CytoTox $96^{\circledR}$ Non-Radioactive Cytotoxicity Assay. From the PC 12 cell suspensions that were exposed to EMF radiation, $25 \mu \mathrm{L}$ was withdrawn onto a 96-well plate (Sarstedt) and $25 \mu \mathrm{L}$ of LDH Mix was added. The samples were incubated for 30 minutes at $25^{\circ} \mathrm{C}$ away from light. Afterward, $25 \mu \mathrm{L}$ of the LDH stopping solution was added and the absorbance was read at $490 \mathrm{~nm}$ using the FLUOstar Omega microplate reader (BMG LABTECH). The percentage release of $\mathrm{LDH}$ was then analyzed.

\section{Statistical analysis}

Statistical data processing was conducted using SPSS 24.0 (IBM Corporation, Armonk, NY, USA). Statistically significant differences $(P<0.05, P<0.01)$ among the various groups were calculated using a one-way ANOVA analysis followed by a post hoc Tukey's multiple comparison test. The independent variables in the study were the three different conditions of treatment.

\section{Results and discussion}

The dosimetry results confirmed that PC 12 cells in suspension exposed to EMF of $18 \mathrm{GHz}$ had a SAR value of $1.17 \mathrm{~kW}$ $\mathrm{kg}^{-1}$, assuming no heat loss to the surrounding solution. Some heat loss to the medium can be neglected as the constituents are similar to that of water with a specific heat capacity of 4.18 $\mathrm{kJ} \mathrm{kg}^{-1 \circ} \mathrm{C}^{-1}$. The rate of change of temperature was $0.28^{\circ} \mathrm{C}$ per second (Figure 1C) during the first 30 seconds of exposure. The time of exposure was reduced to maintain the temperature below $37^{\circ} \mathrm{C}$. The average temperature of the cell suspension after one 30 -second cycle was recorded as $34.94^{\circ} \mathrm{C} \pm 1.73^{\circ} \mathrm{C}$. To investigate the likely contribution of dielectric heating resulting from the absorption of MW radiation by the molecules to the observed changes in nanosphere uptake and cell metabolism, the temperature conditions experienced by the cells during EMF treatment were approximated by subjecting cells to Peltier heating/cooling where the temperature profile in the absence of EMF was replicated, outlined in the Peltier heating/cooling diagram (Figure 1D).
Exposure to EMFs of $18 \mathrm{GHz}$ triggered a transient increase in membrane permeability in the PC 12 cells, as confirmed by rapid internalization of silica nanospheres $(\mathrm{d}=23.5 \mathrm{~nm})$ evident in CLSM and TEM images (Figures 2A and 3 ). It was confirmed by DLS that in the working solution, the nanospheres appeared in clusters of 3-4 nanospheres, with the average size of the majority of the clusters being $\sim 63.9 \mathrm{~nm}$ (Figure 2B). Approximately $90 \%$ of the PC 12 cell population was able to uptake the nanospheres after EMF exposure, while the nanosphere uptake by the heat-treated and the untreated PC 12 cells was negligible, at $1 \%-2 \%$.

Internalization of silica nanospheres of $23.5 \mathrm{~nm}$ was further confirmed by TEM images (Figure 4). Nanospheres in working solutions were found to be monodispersed and in clusters. It appeared that the EMF-treated PC 12 cells internalized the nanospheres (red circles) and their clusters (green insets) and were located inside the cell cytoplasm. No internalized nanospheres were detected on TEM images for the control or the heat-treated sample groups.

It can be concluded that EMF-induced cell membrane permeability in PC 12 cells lasted for 9 minutes following exposure (Figure 3). The PC 12 cells were not permeable after 10 minutes following exposure and permeability was tested at four different time points (3, 6, 9, and 10 minutes) (Figure 3). Previous results established that the internalization of silica nanospheres by bacterial cells continued up to 9 minutes after initial exposure and no uptake of the nanospheres was detected when the nanospheres were added 10 minutes after the initial exposure, ${ }^{10}$ which was similar to the results obtained after exposing EMF-treated PC 12 cells to nanospheres.

The concentration of the nanospheres in the EMF-exposed suspension was calculated to be $0.0031 \mu \mathrm{g} / \mathrm{mL}$. By dividing the mass of a single nanosphere, the number of internalized nanospheres was estimated to be $1.7 \times 10^{11}$ nanospheres. Since the cell concentration was 60,000 cells $/ \mathrm{mL}$, the number of internalized nanospheres per PC 12 cell was calculated to be $2.8 \times 10^{6}$ nanospheres. This was 100 times more than the number of nanospheres internalized by Saccharomyces cerevisiae cells in a previous study, which estimated it to be $2.8 \times 10^{4}$ nanospheres per cell. ${ }^{12}$ It should be noted that yeast cells have a mean diameter of 5.5-5.9 $\mu \mathrm{m},{ }^{20}$ whereas PC 12 cells have a diameter of $\sim 10-12 \mu \mathrm{m},{ }^{21}$ which is twice the size of a single yeast cell.

Analysis of cell morphology using SEM revealed no significant differences between cells in EMF-treated, heattreated, and control groups (Figure 5; top row). No leakage of cytosol was observed in the EMF-treated samples. 

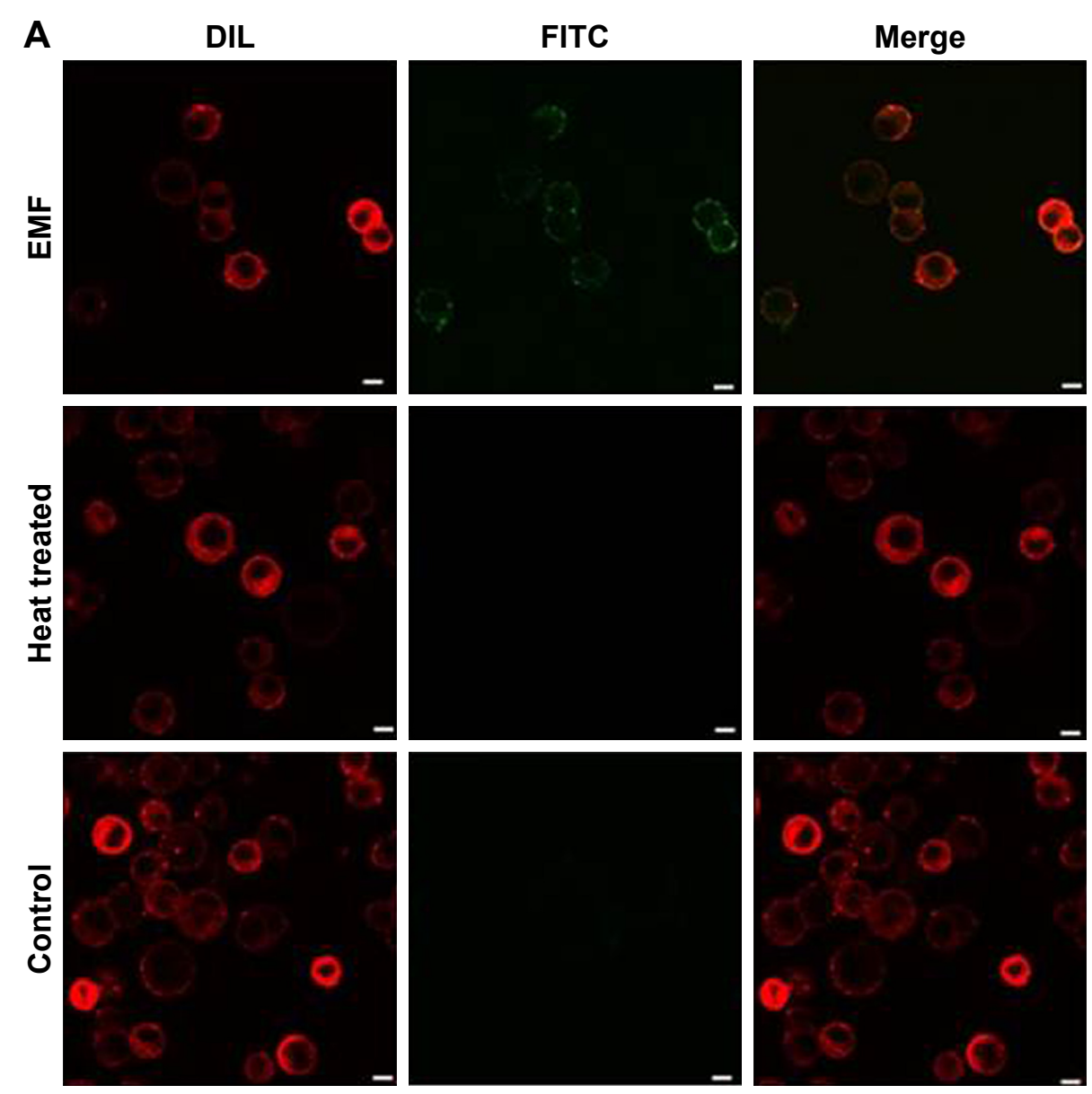

B

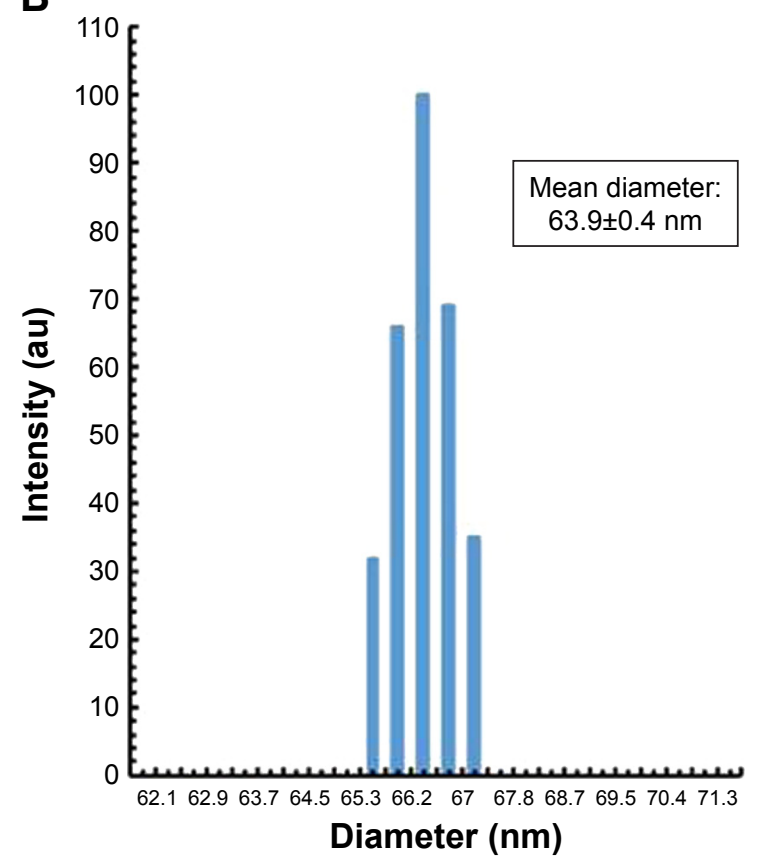

Figure 2 Silica nanosphere internalization of PC 12 cells following EMF exposure.

Notes: (A) CLSM images showing fluorescent silica nanospheres being internalized by PC 12 cells after being exposed to EMF radiation. Scale bar: $5 \mu$ m. (B) Characterization of silica nanospheres clusters in working solution. DLS results for silica nanospheres after sonication ( 15 minutes) revealed that the nanospheres are present in clusters of 3-4 as an effective diameter of $63.9 \mathrm{~nm}$ was recorded.

Abbreviations: EMF, electromagnetic field; DLS, dynamic light scattering; CLSM, confocal laser scanning microscopy; FITC, fluorescein isothiocyanate. 

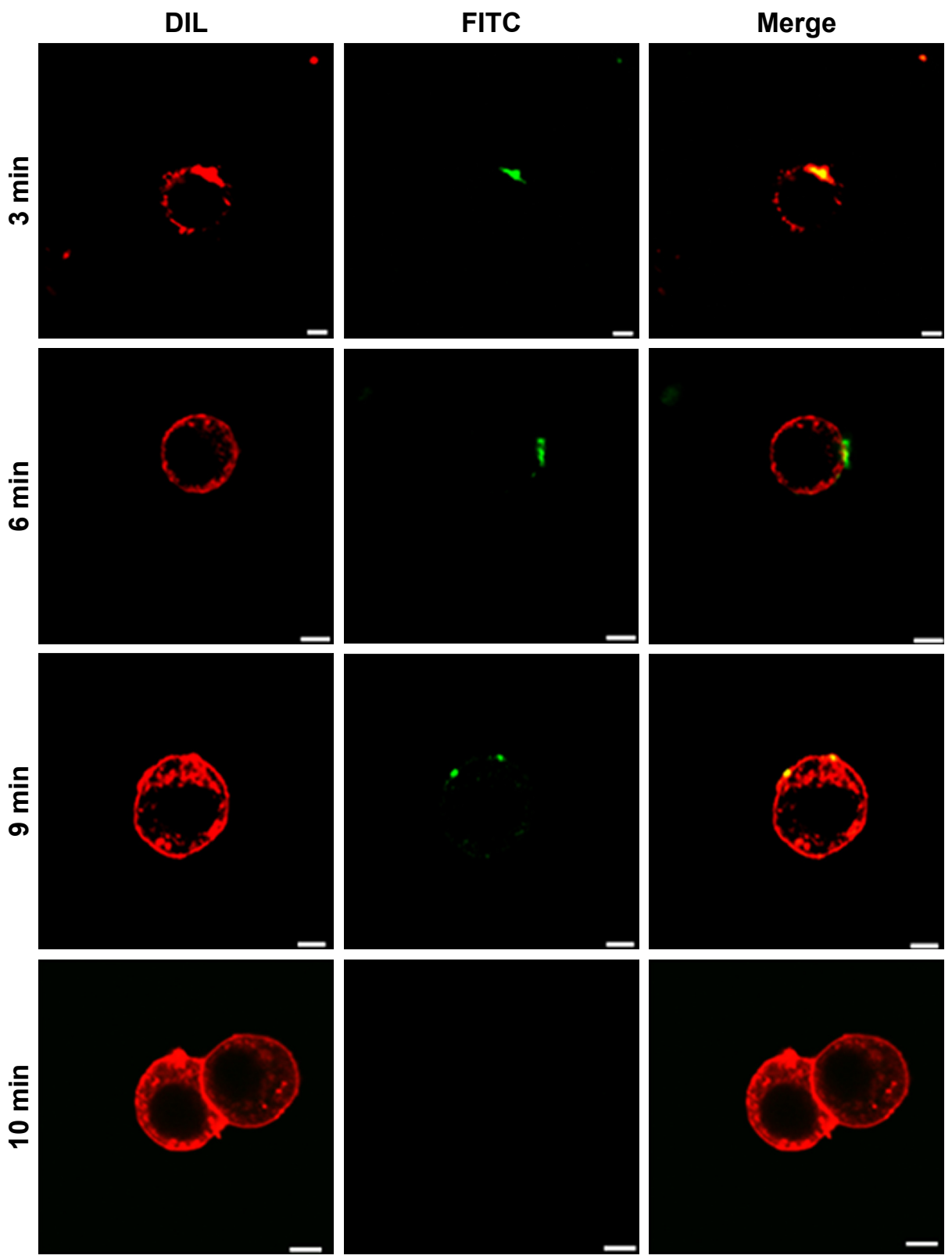

Figure 3 Duration of PC 12 cell permeability following EMF radiation exposure.

Notes: CLSM images showing fluorescent silica nanospheres being internalized by PC 12 cells, 3, 6, and 0 minute after EMF exposure. No nanosphere uptake was detected after 10 minutes. The results suggest that cell permeability lasted for 9 minutes. Scale bar: $5 \mu \mathrm{m}$.

Abbreviations: EMF, electromagnetic field; CLSM, confocal laser scanning microscopy; FITC, fluorescein isothiocyanate.

Viability of PC 12 cells after their exposure to the EMF radiation was investigated using CLSM. Visual examination of the fluorescence micrographs showed that the cells remained viable after EMF treatment (Figure 5; middle row), indicating that the exposure to the EMF of $18 \mathrm{GHz}$ did not affect cell viability. A statistical analysis of the data did not reveal a statistically significant difference between the viability of the EMF-treated and the Peltier-heated cells $(P>0.05)$, EMF-treated cells and the untreated control $(P>0.05)$, or Peltier-treated cells and the untreated control $(P>0.05)$ (Figure 5). This finding is in agreement with previously reported data showing that a 24-hour exposure of human neuroblastoma cells (SH-SY5Y) to MW radiation at a lower frequency $(900 \mathrm{MHz})$ and exposure level $(2 \mathrm{~W} / \mathrm{kg}$ ) did not lead to cell death or increased rates of apoptosis. ${ }^{22}$ This finding has a potentially important implication for the use of high-frequency EMF treatment as a physical means to achieve a temporary increase in membrane permeability for, eg, drug or genetic material delivery, where cell death is undesirable.

The relative metabolic activity of the cells was analyzed using an MTS assay. Increased metabolic activity was 


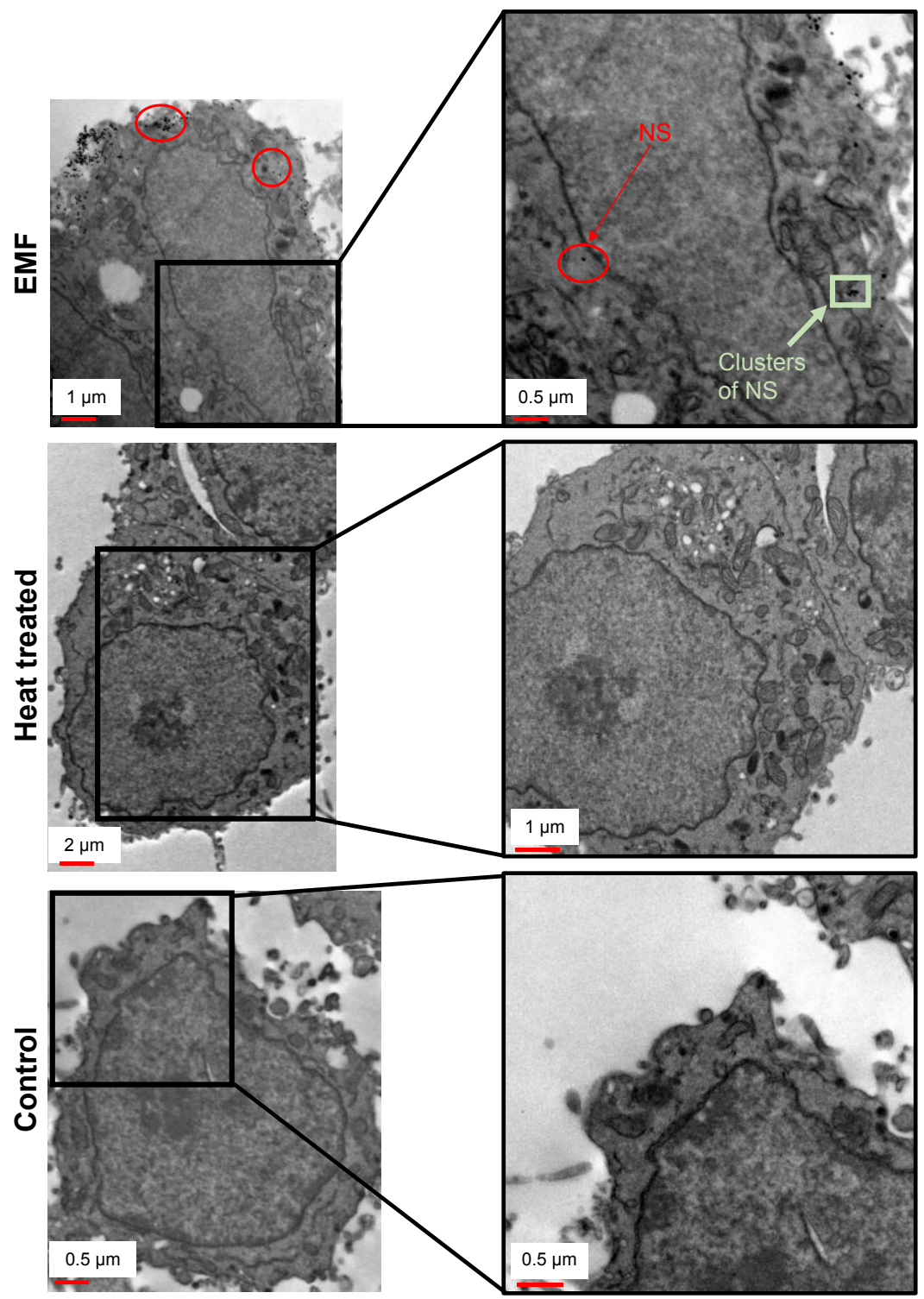

Figure 4 Silica nanospheres internalization by EMF-treated PC 12 cells.

Notes: Typical TEM images showed that PC 12 cells exposed to an EMF of I8 GHz were able to internalize silica nanospheres (23.5 nm) and clusters (63.9 nm) as indicated by arrows. No nanosphere internalization was detected in the heat-treated and control groups. Nanospheres were also seen to cluster around the radiated cells (red circles). Abbreviations: EMF, electromagnetic field; TEM, transmission electron microscopy.

detected in the EMF-exposed PC 12 cells (Figure 6A). The absorbance recorded at $490 \mathrm{~nm}$ was directly proportional to the cell metabolic activity, as mitochondrial activity of metabolically active cells results in the conversion of MTS (salt) into soluble formazan. ${ }^{23}$ Reduction of MTS mainly occurs in the mitochondria, hence providing a measure of mitochondrial function. The latter is an important indicator of cell health, since mitochondrial injury is considered to be an early step in apoptotic cell death. ${ }^{24}$ Previously, it was shown that an EMF of $2.8 \mathrm{GHz}$ with an average power of $30 \mathrm{~mW} / \mathrm{cm}^{2}$ used to treat $\mathrm{PC} 12$ for 5 and 15 minutes triggered some key apoptotic events as a result of the treatment, including the loss of mitochondria membrane potential and DNA fragmentation. ${ }^{8}$
The 18-GHz EMF-treated cells exhibited a slightly higher metabolic activity in comparison to the heat-treated cells and the untreated control. Even though a higher absorbance was recorded, the statistical analysis showed no statistically significant differences among EMF-treated and the Peltierheated cells $(P>0.05)$, EMF-treated and the untreated control cells $(P>0.05)$, or Peltier-treated cells and the untreated control $(P>0.05)$ (Figure 6). In another study, where the enzymatic activity of acetylcholinesterase (AChE) in PC 12 cells was investigated by exposing the cells to $1.8-\mathrm{GHz}$ 217 Global System for Mobile Communication (GSM) for 24 hours, ${ }^{25}$ it was found that subsequent to the treatment, the enzymatic activity increased 1.4-fold in comparison to the untreated control groups. ${ }^{25}$ 
A
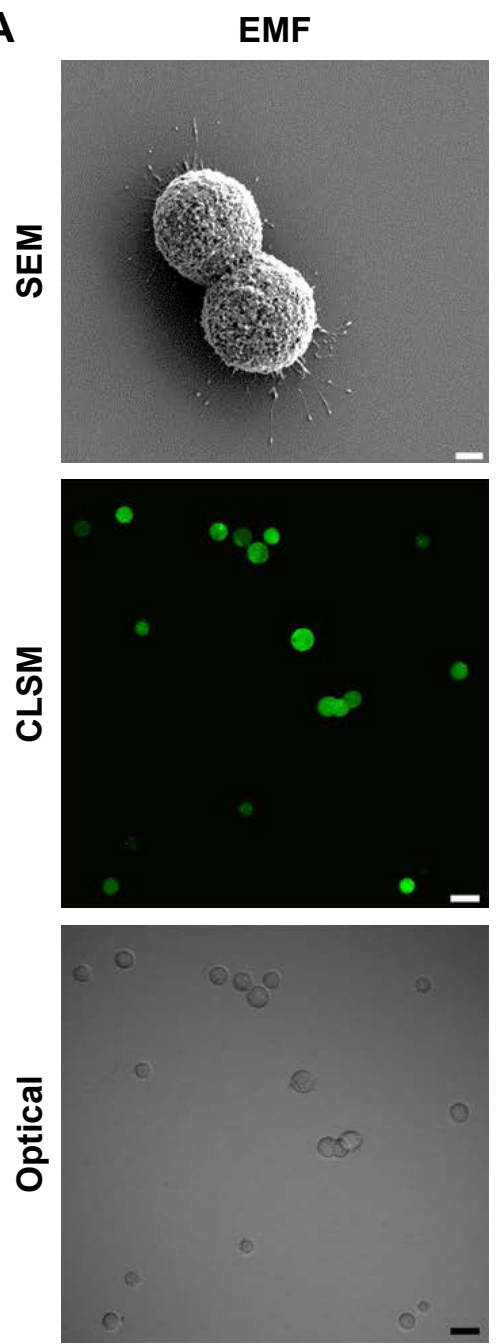

Heat-treated
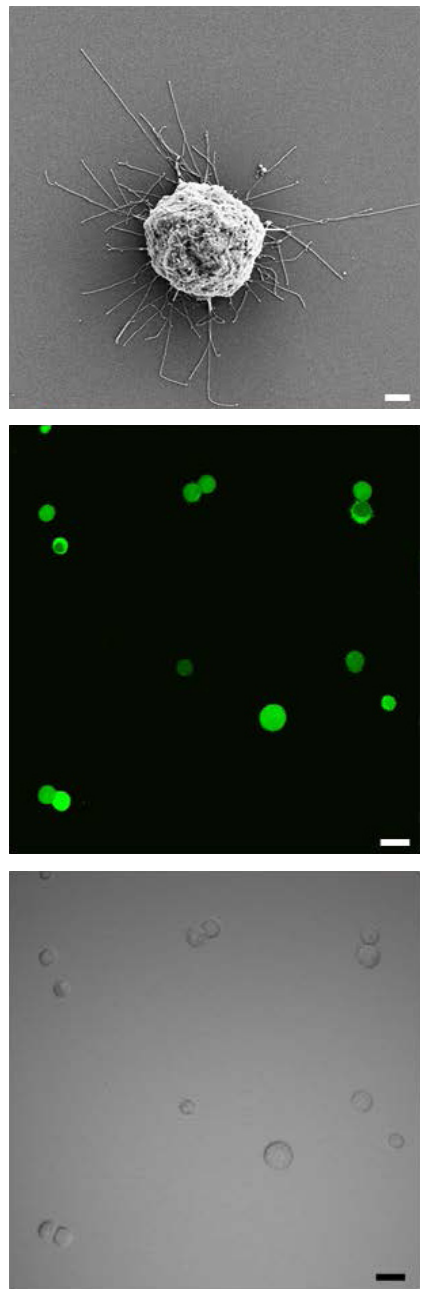

B

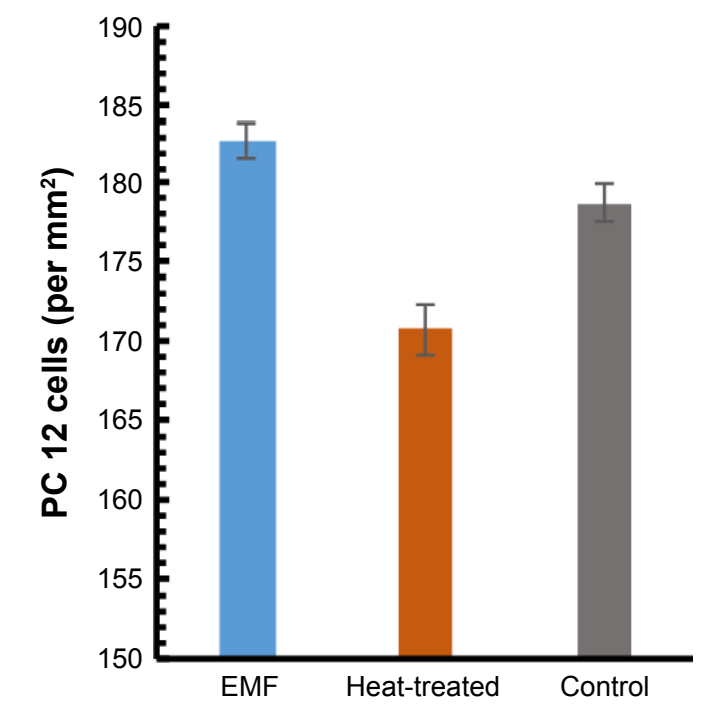

EMF

\section{Control}
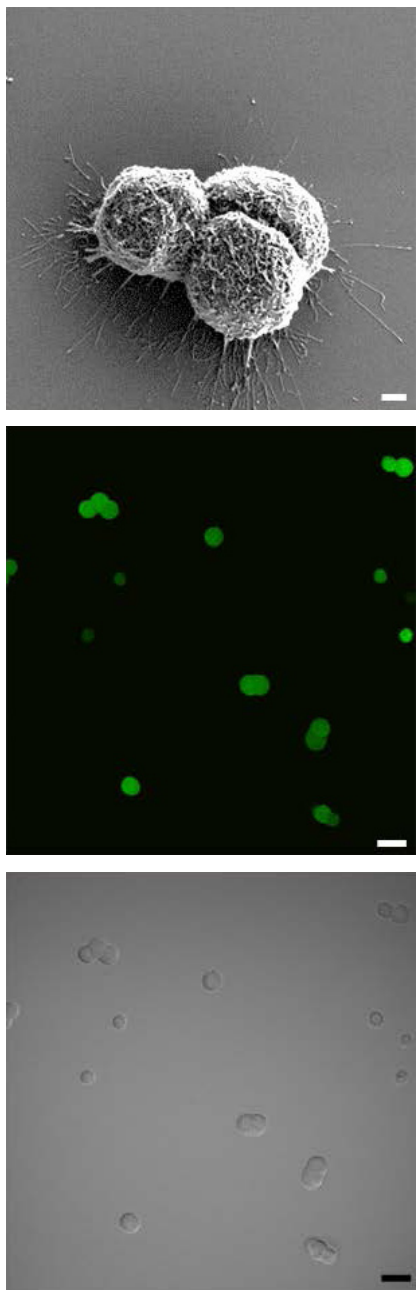

Figure 5 Morphology and viability of PC 12 cells after exposure to EMF radiation.

Notes: (A) Scanning electron micrographs (top row) of PC 12 cells after being exposed to EMF radiation. No significant changes in cell morphology were detected in the EMF-treated groups in comparison to the heat-treated and control samples. Scale bar: $2 \mu \mathrm{m}$. CLSM images (middle row) indicated cell viability, PC I 2 cells exposed to EMF, heat treatments, and the control all remained viable. Phase contrast (bottom row, optical) images of the same field of view. Scale bar: $5 \mu$ m. (B) Quantification of viable PC 12 cells after exposure to EMF radiation. The number of viable cells in the EMF-treated and the other control groups varied slightly; no significant changes ( $P>0.05)$ were detected. Data are presented as mean \pm SD and are representative of three independent repeat experiments.

Abbreviations: EMF, electromagnetic field; SEM, scanning electron microscopy; CLSM, confocal laser scanning microscopy. 

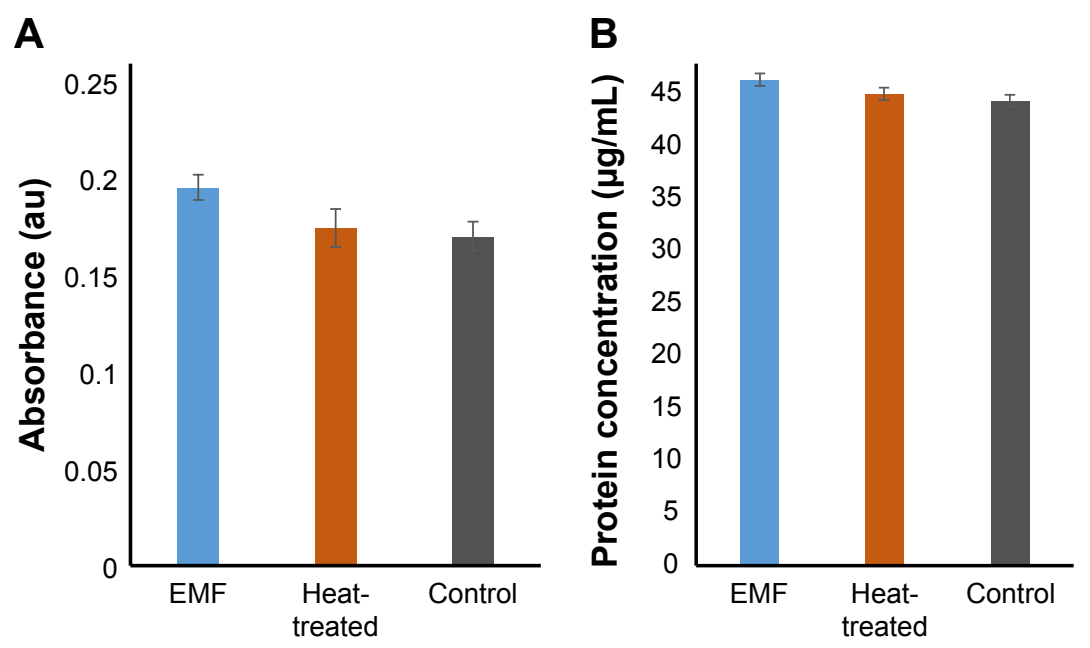

C

Figure 6 PC 12 cells response to EMF radiation.

Notes: (A) Metabolic activity (MTS). (B) Total protein concentration (BCA) of PC 12 cells. The metabolic activity of PC 12 cells in response to EMF radiation appeared to be slightly higher than the heat-treated and the control samples but there is no statistically significant difference $(P>0.05)$ in the absorbance values recorded for the EMF and the control. No significant change in protein concentration was detected in the EMF-treated groups, the heat-treated, and the control groups. (C) LDH release by PC I 2 cells. The degree of LDH release of the EMF-treated and the other groups did not display any significant differences. Data are expressed as mean \pm SD and are representative of three independent experiments $(P>0.05)$.

Abbreviations: EMF, electromagnetic field; BCA, bicinchoninic acid protein assay; LDH, lactate dehydrogenase.

The total protein content of the PC 12 cells was assessed using the BCA assay (Figure 6). The method employs the reduction of $\mathrm{Cu}+{ }^{2}$ by proteins into a purple complex that can be quantified at $562 \mathrm{~nm} .{ }^{26}$ The total protein concentration of EMF-treated cells was found to be $46.4 \pm 0.0092 \mu \mathrm{g} / \mathrm{mL}$, whereas heat-treated samples had a total protein concentration of $45.0 \pm 0.02 \mu \mathrm{g} / \mathrm{mL}$, and the untreated controls had a protein content of $44.4 \pm 0.02 \mu \mathrm{g} / \mathrm{mL}$. Statistical analysis did not indicate any statistically significant difference in the protein concentration between EMF-treated, heat-treated, and non-treated cells $(P=0.636)$ (Figure 6).

The LDH release from the cells was analyzed in order to assess the integrity of the plasma membrane following the EMF exposure (Figure 6). LDH is a stable enzyme present in the cell cytoplasm in all types of cells. Cells typically release LDH into the cell culture medium when their plasma membranes are damaged, and the assay relies on measuring the $\mathrm{LDH}$ activity, where NADH is reduced to $\beta$-nicotinamide adenine dinucleotide. ${ }^{27}$ The percentage of LDH release was calculated after obtaining the maximum level of LDH released after complete cell lysis. The level of release of LDH in the case of the EMF-treated sample and the control group was similar; however, this can be attributed to the baseline LDH that is typically present in the serum-enriched medium used for cell growth. ${ }^{28}$ The already present LDH would thus contribute to the background LDH absorbance. In the heattreated samples, however, a higher level of release of LDH was noted when compared to that in the EMF-treated and the untreated control groups. Statistical analysis revealed no statistically significant difference among all the groups, ie, EMF-treated and the Peltier-heated cells $(P>0.05)$, EMFtreated cells and the untreated control $(P>0.05)$, Peltiertreated cells and the untreated control $(P>0.05)$ (Figure 6).

Thus, the results obtained in this study provide evidence that the exposure of PC 12 cells to EMFs of $18 \mathrm{GHz}$ induced a significant increase in membrane permeability without compromising morphology, viability, or metabolic activity of the treated cells. These results are in good agreement with those from previous reports that showed that the ability of EMF of $18 \mathrm{GHz}$ induced a reversible increase in membrane permeability in different Gram-negative and Gram-positive bacterial species, including P. maritimus KMM 3738, S. aureus CIP65.8 ${ }^{\mathrm{T}}$, S. aureus ATCC 25923 , S. epidermidis ATCC $14990^{\mathrm{T}}$, and E. coli, and yeast and red blood cells. ${ }^{10,11}$

In light of this body of evidence, it can be suggested that the phenomenon of cell membrane permeabilization as a result of the exposure of cells to an EMF of $18 \mathrm{GHz}$ is different from other cell poration phenomena achieved using a variety of techniques, including mechanical stress, sonoporation, electroporation, and photoporation. ${ }^{29-31}$ For instance, sonoporation techniques cause permeabilization by means of ultrasound (frequency of $20 \mathrm{kHz}$ with an intensity of $5-55 \mathrm{~W} / \mathrm{cm}^{2}$ ) continuously applied to cells for 30 seconds -5 minutes, with resulting pore sizes of 1-100 $\mu \mathrm{m} .{ }^{32}$ Therapies based on electroporation involve 
placing electrodes around or within a target tissue while delivering a series of $8-100$ short $(\sim 100 \mu \mathrm{s})$ electric pulses of high voltage $(\sim 1,000-3,000 \mathrm{~V}) .{ }^{33}$ Photoporation delivers foreign material into cells using light generated by laser diodes operating at $450 \mathrm{~nm}$ at $0.3 \mathrm{~mW}$ for $40 \mathrm{~ms}^{34}$

Similar to other cell poration techniques, exposure to EMFs of $18 \mathrm{GHz}$ could be used as a means to facilitate more effective delivery of drugs, genes, and nanoparticles into a cell for the purpose of cellular manipulation or therapy, eg, by enhancing the uptake of chemotherapeutic drugs for cancer treatment. ${ }^{29,35}$ The 18-GHz EMF may act as external stimuli, which can initiate membrane depolarization leading to permeability. Exposure of an artificial axon model to a 53.37GHz EMF (SAR 1.1-1.6 GHz) has been shown to increase both the transmembrane $\mathrm{K}+$ efflux from lipid vesicles and the transport of these ions across the lipid membrane by promoting the activity of the $\mathrm{K}+$ carrier valinomycin, thereby affecting the amplitude of electrical signals that propagate through electrically excitable cells. ${ }^{36}$ Furthermore, a review of 23 studies has suggested that voltage-gated calcium channels may be activated upon exposure to EMFs, with downstream responses mediated through $\mathrm{Ca}^{2+} /$ calmodulin stimulation of nitric oxide synthesis and subsequent stimulation of the $\mathrm{NO}$-cGMP-protein kinase $\mathrm{G}$ and $\mathrm{NO}-\mathrm{ONOO}^{-}$-oxidative stress pathways, where the former can have therapeutic and the latter pathophysiological bioeffects, as well as responses mediated by other processes regulated by $\mathrm{Ca}^{2+} .{ }^{37}$ Evidence of EMF-induced oxidative stress in cells has been observed after repeated subject exposure to 9-GHz EMFs (SAR 0.4 W/kg), ${ }^{38}$ with oxidative damage such as single-strand DNA breaks shown in tissues exposed to 2.45- and 16.5-GHz EMFs (SAR 1.0 and $2.01 \mathrm{~W} / \mathrm{kg}$, respectively). ${ }^{39}$ The EMF-induced formation of reactive oxygen species, such as peroxynitrite, may result in lipid peroxidation and oxidation of proteins within the cellular membrane, thereby changing membrane fluidity, and affecting pore formation and resealing, and cell metabolism and viability. ${ }^{40}$

However, a similar nature of pore formation across multiple cell types that contain different levels of voltagegated channels treated with $18-\mathrm{GHz}$ EMFs indicates that, in this case, the formation of pores may take place at the level of the lipid bilayer, independently of the voltage-gated channels. ${ }^{41}$ Furthermore, in this study, the viability, metabolic activity, and membrane functional integrity of cells treated with 18-GHz EMF were not affected by the exposure.

Based on the results of this and previous studies that have used 18-GHz EMFs, it is clearly evident that the EMFinduced increase in permeability is not likely to originate from bulk heating of the suspension since exposure of cells to similar temperatures in the absence of MW radiation failed to induce cell permeabilization. This leads us to believe that the observed effect is likely to be electrokinetic in nature due to the increased conductivity and mobility of ions across the cell membrane, with potential contribution from microthermal changes that cannot be easily captured at the macro level, as well as from the direct interaction of the EMF with cell membranes and/or their structural and functional components (eg, phospholipids). ${ }^{10,12,13}$ Indeed, it is well known that when a polarized, nonionizing electromagnetic oscillation encounters a polar or charged molecule, it transfers a fraction of its energy to this molecule, driving it to oscillate. The degree of the thus-induced oscillation is greatest for unbound electrically charged particles, such as free ions that abound human tissues. ${ }^{18}$ Additional energy will be absorbed by the water dipoles, as well as by larger polar or charged molecules, including biological macromolecules such as nucleic acids, lipids, and proteins. These interactions will also result in oscillations due to the applied EMFs; however, the magnitude of such energy absorption or oscillation is more difficult to estimate due to the bound nature of many such molecules. Yet, they may play an important role in the development of EMF-induced membrane permeability. Furthermore, the application of an EMF may also induce a local elastic tension through Maxwell's tensor, forcing the membrane to which the field is applied to prolate or oblate, with the result dependent on the properties of the EMF and the mechanical properties of the membrane. ${ }^{42,43}$

In summary, in this work, we have explored the potential of 18-GHz EMF treatment to induce transient permeabilization of cell membrane in a mammalian cell model without any detrimental effect to cell viability or metabolism, thereby providing a potential alternative to conventional poration techniques in drug delivery applications.

\section{Acknowledgments}

This work was partly supported by the Australian Centre for Electromagnetic Bioeffects Research and National Health and Medical Research Council Centre of Research Excellence. The authors would like to acknowledge the assistance provided by the RMIT Microscopy and Microanalysis Facility.

\section{Disclosure}

The authors report no conflicts of interest in this work. 


\section{References}

1. Banik S, Bandyopadhyay S, Ganguly S. Bioeffects of microwave - a brief review. Bioresour Technol. 2003;87(2):155-159.

2. Redlarski G, Lewczuk B, Żak A, et al. The influence of electromagnetic pollution on living organisms: historical trends and forecasting changes. Biomed Res Int. 2015.

3. Oliveira E, Santos HM. An overview on sensing materials depending on the electromagnetic spectra region applied. Dyes Pigm. 2016;135:3-25.

4. Sokolovic D, Djindjic B, Nikolic J, et al. Melatonin reduces oxidative stress induced by chronic exposure of microwave radiation from mobile phones in rat brain. J Radiat Res. 2008;49(6):579-586.

5. Salford LG, Brun A, Persson BRR. Brain tumour development in rats exposed to electromagnetic fields used in wireless cellular communication. Wireless Networks. 1997;3(6):463-469.

6. Deshmukh PS, Megha K, Nasare N, et al. Effect of Low Level Subchronic Microwave Radiation on Rat Brain. Biomed Environ Sci. 2016; 29(12):858-867.

7. Lewczuk B, Redlarski G,Zak A, Ziółkowska N, Przybylska-GornowiczB, Krawczuk M. Influence of electric, magnetic, and electromagnetic fields on the circadian system: current stage of knowledge. Biomed Res Int 2014;2014:169459.

8. Zuo H, Lin T, Wang D, et al. Neural cell apoptosis induced by microwave exposure through mitochondria-dependent caspase-3 pathway. Int J Med Sci. 2014;11(5):426-435.

9. Shamis Y, Croft R, Taube A, Crawford RJ, Ivanova EP. Review of the specific effects of microwave radiation on bacterial cells. Appl Microbiol Biotechnol. 2012;96(2):319-325.

10. Nguyen TH, Shamis Y, Croft RJ, et al. $18 \mathrm{GHz}$ electromagnetic field induces permeability of Gram-positive cocci. Sci Rep. 2015;5:10980.

11. Shamis Y, Taube A, Mitik-Dineva N, Croft R, Crawford RJ, Ivanova EP. Specific electromagnetic effects of microwave radiation on Escherichia coli. Appl Environ Microbiol. 2011;77(9):3017-3022.

12. Nguyen TH, Pham VT, Nguyen SH, et al. The bioeffects resulting from prokaryotic cells and yeast being exposed to an $18 \mathrm{GHz}$ electromagnetic field. PLoS One. 2016;11(7):e0158135.

13. Shamis Y, Traub A, Croft R, Crawford R, Ivanova EP. Influence of $18 \mathrm{GHz}$ microwave radiation on the enzymatic activity of Escherichia coli lactate dehydrogenase and cytochrome c oxidase. J Phys Sci Appl. 2012;2(6):143-151.

14. Woo IS, Rhee IK, Park HD. Differential damage in bacterial cells by microwave radiation on the basis of cell wall structure. Appl Environ Microbiol. 2000;66(5):2243-2247.

15. Jesky R, Chen H. The neuritogenic and neuroprotective potential of senegenin against Abeta-induced neurotoxicity in PC 12 cells. BMC Complement Altern Med. 2016;16:26.

16. Westerink RH, Ewing AG. The PC12 cell as model for neurosecretion. Acta Physiol. 2008;192(2):273-285.

17. Greene LA, Tischler AS. Establishment of a noradrenergic clonal line of rat adrenal pheochromocytoma cells which respond to nerve growth factor. Proc Natl Acad Sci U S A. 1976;73(7):2424-2428.

18. Panagopoulos DJ, Johansson O, Carlo GL. Evaluation of specific absorption rate as a dosimetric quantity for electromagnetic fields bioeffects. PLoS One. 2013;8(6):e62663.

19. Haemmerich D, Schutt DJ, dos Santos I, Webster JG, Mahvi DM. Measurement of temperature-dependent specific heat of biological tissues. Physiol Meas. 2005;26(1):59-67.

20. Srinorakutara T. Determination of yeast cell wall thickness and cell diameter using new methods. J Ferment Bioeng. 1998;86(3):253-260.

21. Sagi Y, Basser PJ, Assaf Y. Estimation of Cell Size Using the Composite Hindered and Restricted Model of Diffusion. Magn Reson Med. 2009; $17: 1390$.

22. Joubert V, Leveque P, Rametti A, Collin A, Bourthoumieu S, Yardin C. Microwave exposure of neuronal cells in vitro: Study of apoptosis. Int J Radiat Biol. 2006;82(4):267-275.
23. Malich G, Markovic B, Winder C. The sensitivity and specificity of the MTS tetrazolium assay for detecting the in vitro cytotoxicity of 20 chemicals using human cell lines. Toxicology. 1997;124(3): 179-192.

24. Lobner D. Comparison of the LDH and MTT assays for quantifying cell death: validity for neuronal apoptosis? J Neurosci Methods. 2000;96(2): 147-152.

25. Valbonesi P, Franzellitti S, Bersani F, Contin A, Fabbri E. Activity and expression of acetylcholinesterase in PC12 cells exposed to intermittent $1.8 \mathrm{GHz}$ 217-GSM mobile phone signal. Int J Radiat Biol. 2016; 92(1):1-10.

26. Smith PK, Krohn RI, Hermanson GT, et al. Measurement of protein using bicinchoninic acid. Anal Biochem. 1985;150(1):76-85.

27. Han X, Gelein R, Corson N, et al. Validation of an LDH assay for assessing nanoparticle toxicity. Toxicology. 2011;287(1-3):99-104.

28. Hiebl B, Peters S, Gemeinhardt O, Niehues SM, Jung F. Impact of serum in cell culture media on in vitro lactate dehydrogenase (LDH) release determination. J Cell Biotechnol. 2017;3(1):9-13.

29. Hansen EL, Sozer EB, Romeo S, Frandsen SK, Vernier PT, Gehl J. Dose-dependent ATP depletion and cancer cell death following calcium electroporation, relative effect of calcium concentration and electric field strength. PLoS One. 2015;10(4):e0122973.

30. Zu Y, Huang S, Liao WC, Lu Y, Wang S. Gold nanoparticles enhanced electroporation for mammalian cell transfection. J Biomed Nanotechnol. 2014;10(6):982-992.

31. Sadiq AA, Zaltum MAM, Mamman HB, et al. An overview: investigation of electroporation and sonoporation techniques. Inst Electrical Electron Eng. 2015:1-6.

32. Sheikh S, Pallagatti S, Singh B, Puri N, Singh R, Sonoporation KA. A redifined ultrasound modality as therapeutic aid: A review. J Clin Exp Dent. 2011;3(3):e228-e234.

33. Garcia PA, Davalos RV, Miklavcic D. A numerical investigation of the electric and thermal cell kill distributions in electroporation-based therapies in tissue. PLoS One. 2014;9(8):e103083.

34. Paterson L, Agate B, Comrie M, et al. Photoporation and cell transfection using a violet diode laser. Opt Express. 2005;13(2):595-600.

35. Geng T, Lu C. Microfluidic electroporation for cellular analysis and delivery. Lab Chip. 2013;13(19):3803-3821.

36. D'Agostino S, Della Monica C, Palizzi E, et al. Extremely High Frequency Electromagnetic Fields Facilitate Electrical Signal Propagation by Increasing Transmembrane Potassium Efflux in an Artificial Axon Model. Sci Rep. 2018;8(1):9299.

37. Pall ML. Electromagnetic fields act via activation of voltagegated calcium channels to produce beneficial or adverse effects. J Cell Mol Med. 2013;17(8):958-965.

38. Garaj-Vrhovac V, Gajski G, Pažanin S, et al. Assessment of cytogenetic damage and oxidative stress in personnel occupationally exposed to the pulsed microwave radiation of marine radar equipment. Int J Hyg Environ Health. 2011;214(1):59-65.

39. Paulraj R, Behari J. Single strand DNA breaks in rat brain cells exposed to microwave radiation. Mutat Res. 2006;596(1-2):76-80.

40. Gabriel B, Teissié J, Bruno G, Justin T. Generation of reactiveoxygen species induced by electropermeabilization of Chinese hamster ovary cells and their consequence on cell viability. Eur J Biochem. 1994;223(1):25-33.

41. Dermol-Černe J, Miklavčič D, Reberšek M, et al. Plasma membrane depolarization and permeabilization due to electric pulses in cell lines of different excitability. Bioelectrochemistry. 2018;122: 103-114.

42. Portet T, Mauroy C, Démery V, et al. Destabilizing giant vesicles with electric fields: an overview of current applications. J Membr Biol. 2012;245(9):555-564.

43. Goldberg E, Suárez C, Alfonso M, Marchese J, Soba A, Marshall G. Cell membrane electroporation modeling: A multiphysics approach Bioelectrochemistry. 2018;124:28-39. 


\section{Publish your work in this journal}

The International Journal of Nanomedicine is an international, peerreviewed journal focusing on the application of nanotechnology in diagnostics, therapeutics, and drug delivery systems throughout the biomedical field. This journal is indexed on PubMed Central,

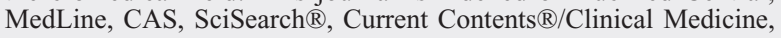

Journal Citation Reports/Science Edition, EMBase, Scopus and the Elsevier Bibliographic databases. The manuscript management system is completely online and includes a very quick and fair peer-review system, which is all easy to use. Visit http://www.dovepress.com/ testimonials.php to read real quotes from published authors.

Submit your manuscript here: http://www.dovepress.com/international-journal-of-nanomedicine-journal 